\title{
Privacy Cognition of Spaces by Agraph Tools in Temperate Humid Climatic Region of Iran
}

\begin{abstract}
Purpose

The aim of this research is to understand the spatial configuration between the spaces by using the space syntax method for close, semiopen and open spaces.

\section{Design/methodology/approcach}

The method of this study is Agraph that is one of the tools of space syntax method. Agraph tool represent spatial relation between the spaces with graph and calculation included. During the research, all the space such as close, semi-open and open spaces analyzed with space syntax method.

\section{Findings}

The finding of this investigation demonstrated that although traditional houses have different topological issue, from different level of economy but the concern of organizing spaces under context and social hierarchy were same between all of them. Furthermore, inhabitants in different level of economy attempt to organize space by concerning privacy and public issue. Designing of traditional building in temperate humid climate is in a way to respond to the harsh climatic condition and to their cultural behavior.
\end{abstract}

\begin{abstract}
Keywords: AGRAPH tool, Iranian traditional building, space syntax, temperate-humid climate.
\end{abstract}

*Assistant Professor Doctor in Architecture department, faculty of fine art design and architecture in Cyprus International University Email: parastoo.pourvahidi@gmail.com ORCID No: https://orcid.org/0000-00030595-5466 


\section{Research Limitations/Implications}

Four different types of Iranian traditional buildings where are located in the temperate-humid climatic region of Iran analyzed for discovering the social relation of the spaces in Gilan province. These four different categories included of one bedroom to more than five bedroom buildings. Hence, this research just considered the analysis for the houses with less than five bedrooms.

\section{Practical Implications}

Applying Agraph tool for understanding privacy and public degree of spaces.

\section{Social Implications}

Applying Agraph tool on Iranian traduational architecture for estimating the degree of privacy in each spaces. Since in Iranian culture spaces organized based on the public and privacy factor.

\section{Originality/Value}

The original of this research is to finding the degrre of privacy in each building with different level of economy based on Agraph tool. However, the result was different from the previuse studies. The consequence of Agraph tool needs some modification for applying in architectural purposes.

\section{INTRODUCTION}

As Vursho illustrated that the place where inhabitant could sleep, eat, live named as the house but architect should understand the activity and accommodation of the inhabitant. From another point of view, arrangement of space represents a house that is demonstrated which type of spaces are grouped together for spatial activity or which one are separated for creating more privacy for the residents (Vursho \& Yunnistyna, 2016).

Dawson (2003) demonstrated that throughout the structure of a house, public spaces are called for the spaces that are more accessible and private spaces are the one which have less accessibility. Hiller and Hansonin their method claimed that with the help of the justified graph, the plan layout, morphological characters can be revealed (Hanson, 1998). Therefore, the purpose of this research is to apply the Agraph tool for the dwelling where are located in temperate humid climatic region for understanding the relation of accessibility with the degree of public and privacy of the spaces by choosing different spaces as a starting point. Finding of this research demonstrated that drawing the graph could give various results for the degree of public and private of spaces. For instance, based on Agraph tools the outcome of calculation, is varied if graph drawn from the entrance as a starting point or another space such as close space (room) and open spaces.

\section{CHARACTERISTIC OF TRADITIONAL BUILDING IN TEMPERATE-HUMID CLIMATE}

Iran has five different climatic regions such as temperate humid (north part of Iran), hot-humid (south part of Iran) hot-dry and hot-dry with cold winter (central part of Iran) and cool climate 
(wester part of Iran) (Pourvahidi \& Ozdeniz, 2013). According to this classification, this study evaluating the traditional houses where are located in north part of Iran (Gilan province). The name of the province where is located on north of Iran under the south part of Caspian Sea is Gilan. This area has a specific climate since it is positioned between Alborz Mountain and Caspian seas.

Life for the inhabitants in north part of Iran always signified the standards of simplicity and honesty of nature. In 2016 based on Rezaeirad investigation, there are two groups of architecture in this temperate humid climatic region of Iran. One type is the rural buildings which demonstrated the inhabitants need with minimum accommodations in nature and the other group is the modern building that constructed with the advance material such ceramic and composite (Rezaeirad, 1998).

According to Princ Diba research on several types of residential building, he claimed that traditional buildings in Iran have been made based on environmental issue. Since, in his evaluation he find out that architectural organization of spaces in these kinds of houses are divided into three categories such as closed spaces like rooms, semi-open spaces like Eyvan and open spaces like courtyard where are mostly located surrounding area of a house (Darab \& Yaghini, 1998).

Yaran and Mehranfar (2013) in their research demonstrated that Gilan province has six architectural typologies. This kind of classification has the root into economic condition and living and social base of the inhabitants. Furthermore, they illustrated that there are some kind of building with maximum two stories. These kinds of houses, in relation to the number of floors that they have, consistent of one, two or three bedrooms and even some of the houses have five and six bedrooms (Yaran, 2013). In the related subject, Sajjadzadeh also mentioned that geography, life style and cultural issue have a direct effect to the relationship between building and the environment in Gilan province. For instance, by comparing Gilan's building with the buildings in the central part of Iran, the lack of boundaries between inside and outside is noticeable (Sajjadzadeh, 2016). Since the building in north (Gilan province) has no any boundary around the building for limiting the axes from outside. They have a short wall and most of the time they use trees for creating limitation. However in central part of Iran, long wall surround the building for creating privacy for the inhabitants. In addition to the relationship between the spaces reflect the activities of residents. This issue has a direct effect of environmental issue beside the cultural thoughts. Consequently, this research endeavor to understand the spatial organization which is 
subjective by environment and culture in Gilan's traditional buildings.

Furthermore, in this research four different kinds of traditional houses has been selected. These traditional houses are located in Gilan province where temperate-humid climate have. Selection of these cases studied is based on the number of rooms from one bedroom to five bedroom, and the reason was based on economic and typological issue.

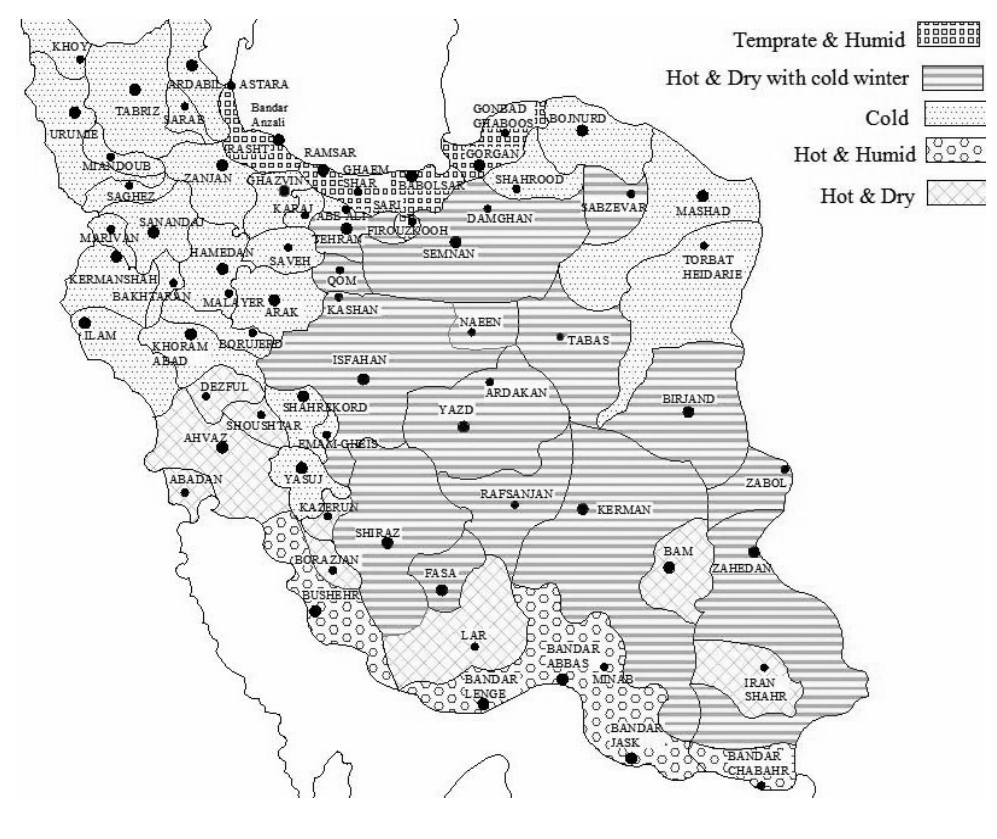

Traditional building in temperate humid climatic region has a main semi-open space which is called Eyvan. Since of humid climatic condition the inhabitants prefer to spend their time in Eyvan during spring and summer where can wind blow through that space and create comfortable condition for the residents. Therefore, Eyvan has a main character for joining the spaces all together. Since mostly it is extended through the surface of a building. This extension of Eyvan in some of the traditional building is from one side, two sides, 3sides or all around the building. Subsequently, this paper divided the case study into four different categories according to the number of rooms and extended Eyvan (Table 1). 
Privacy Cognition of Spaces by Agraph Tools in Temperate Humid Climatic Region of Iran

Table 1: Schematic topologies of traditional buildings plans where are located in the temperate-humid region of Iran

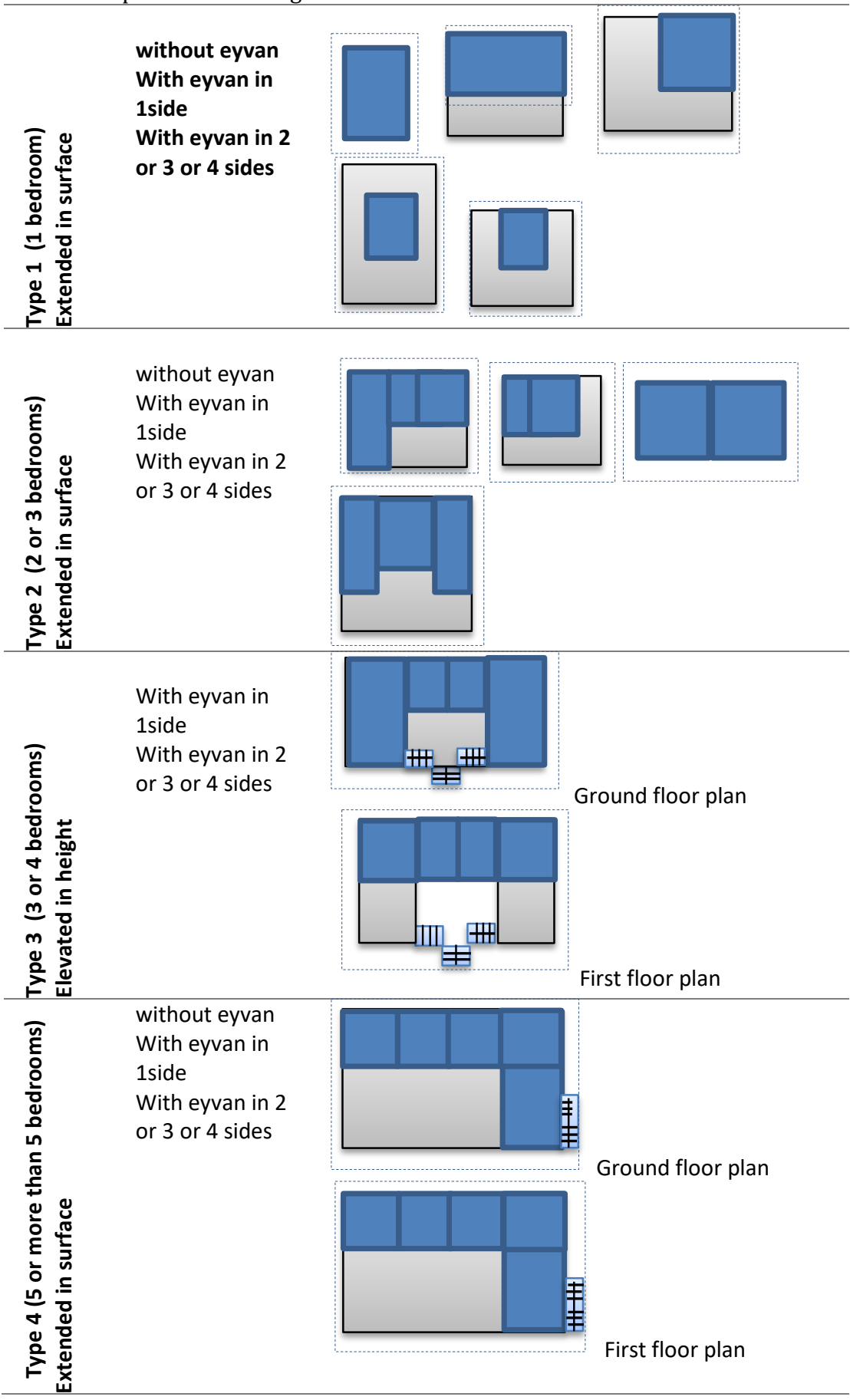

For better understanding the integration and segregation of the spaces in these kinds of traditional building, economy condition is the fact. Since the result of comparing one bed room building with five bedrooms is not accurate. Thus, this research classified them consistent with the level of economic in Table 2. The arrangement was based on the number of the rooms. Moreover, representing the proportion of width to height of these traditional building could be the answer of economic and climatic condition level of them as well. Since, the traditional 
building which is elevated from the ground and extended from east to west and also has two to three floors has better economic and comfortable condition than others. For instance, first floor has better comfortable condition during winter time and also elevated building from ground cause less humidity. Furthermore extending building from east to west can create more windows toward south direction which has best lighting during winter and summer.

Table 2: Schematic classification of traditional buildings consistent with economic conditions.
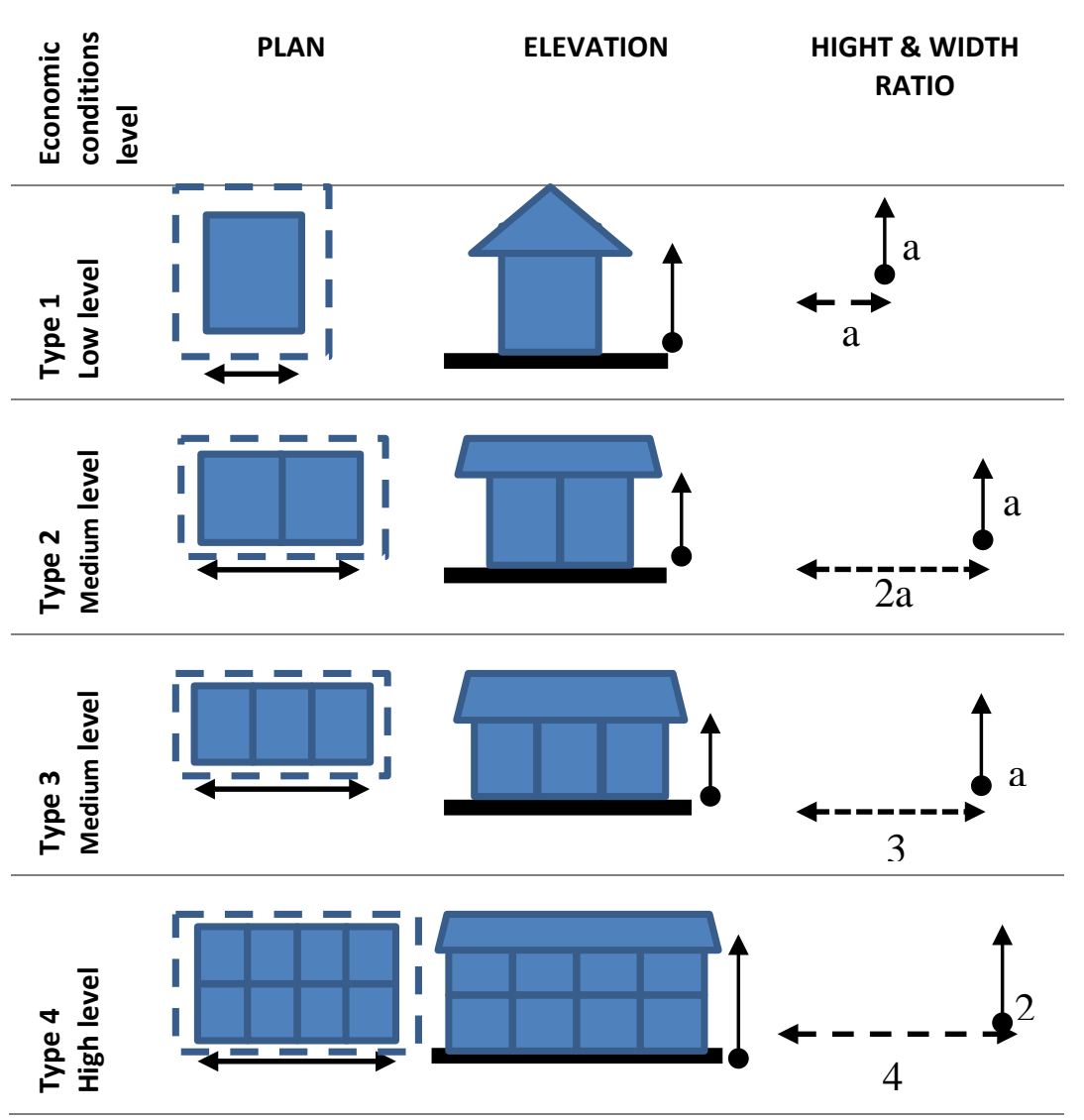

By comprehending the fact that the climatic factor has effect on the formation of spaces in this climatic region. Afterwards, space syntax method which is one of the best method for revealing the accessibility relation between spaces assist the research to do the analyses with Agrap tool for detecting the social relation of the spaces for organizing the spaces in Gilan province. 
Privacy Cognition of Spaces by Agraph Tools in Temperate Humid Climatic Region of Iran

Table 3: Simulating the traditional building according to the climatic conditions

1 Settlement Pattern Diffused

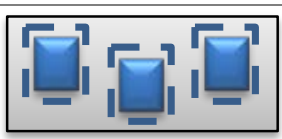

2 Configuration of Extensive
the Building

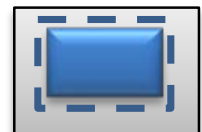

$3 \quad$ Roof $\quad$ Sloped

6 Basement No

\begin{tabular}{ll}
\hline 7 & Elevation of Ground \\
Floor Slab from \\
Ground
\end{tabular}

$8 \begin{aligned} & \text { Extroverted and } \\ & \text { Introverted } \\ & \text { Buildings }\end{aligned}$

Height of the $3 \mathrm{~m}$
Ceiling

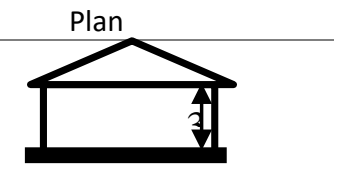

Elevation

\begin{tabular}{llll}
\hline $\mathbf{1 0}$ & Thickness of the & Thin \\
Walls & & \\
\hline $\mathbf{1 1}$ & Natural ventilation & High & \\
\hline $\mathbf{1 2}$ & Openings & High & \\
& & \\
\hline $\mathbf{1 3}$ & Color of the faced & Free \\
\hline $\mathbf{1 4}$ & Material & $\begin{array}{l}\text { Low thermal } \\
\text { capacity }\end{array}$ \\
\hline
\end{tabular}




\section{STUDY APPROACH AND METHODOLOGY}

Some of the researchers such as cultural geographers and anthropologists like Amos Rapoport (Rapoport, 1968), Lawrence and Los (Lawrence, 1990) and Hiller and Hanson (Hiller, 1984), analyzed the built environment in the manner to notice the social, cultural and ideological features of traditional buildings and cities (Blanton, 1994; Martin, 2001; Trigger, 1989)

The analysis of the spatial organization of the built environment has been developed from the perspective of space syntax analysis which was conceived by Bill Hiller and Julienne Hanson ( Hiller, 1984; Hillier, 1996; Hanson, 1998). (Space syntax analyses of the built environment theories and limitations of the space become probable to evaluate the social relationships characteristic in spaces as it is built through the built environment. Marcus (1993, p.13) mentioned that this perception is accepted that all space is formed and shaped by social relationships. This social relation constrains the character of spatial relations in the built environment hence it is fundamentally social (Hillier, 1984).

The significant theoretical idea of space syntax is that space has a social reason that is understandable. It could be assumed the two relationships that can define the logic of space syntax. These relations could be distinct between the inhabitants (private) and other people (public). This kind of impression is not distinctive to Hiller and Hanson's formulation of space syntax. For instance, Urry (1987) also illustrated that there is a significant disagreement between those who are local such as the people like us and those who are non-local such as the outsider. Therefore, this second opposition can be associated and reproduced in different kind of ways. The development of a strong set of analytical techniques and process in to methodologically association theory to the experimental record that is unique to space syntax. Thus, this study investigative on the space organization and social relation of them by using Space syntax method on the case studies included four different types of traditional Iranian building with different economic condition and different topological issue. The analysis followed by drawing justified access graph for each of the case studies by noticing the starting point.

Justified access graph is a kind of graph that represent the plan layout from the morphological characteristic of it. "The carrier" is a selected chosen space which from that space, depth value of all the spaces in one house could be calculated. Depth value of the space is numbered based on the location of the space on a graph. The numeric measurement established on spatial configuration of the graph could be achieved when the graph is formed. Furthermore, as Hanson mentioned the "busy" and "quite" 
characteristic of the spaced could be predictable by the integration and permeability (Hanson, 1998).

According to all these explanations about space syntax method, there are also different kind of software for analyzing spatial analysis such as DepthmapX, Omnivista, Qgis Space Syntax Toolkit (most used by urban planners), Confeego and Axman (most used by researchers) Agraph (to make axial-line analysis) (Manum, 2009). This research has chosen Agraph since it is the simple tool for understanding the spatial organization. Hence, this study used Agraph tool for the analysis of dwelling in Gilan Province. During the analysis, this research changes "the carrier" space (starting point) based on close, semi-open and open space for achieving the proper answer for public (busy) and privacy (quite) of the spaces.

\section{DEFINITION OF AGRAPH TOOL}

The parameters of total depth (TD), control value (CV), relative asymmetry (RA), mean depth (MD) and integrated value (RA) have been calculated with AGRAPH.

"Total depth: Total depth of a node $\mathrm{n}, \mathrm{TD}(\mathrm{n})$ is the total of the shortest distances from node $\mathrm{n}$ to the other nodes in the systems, i.e.TD(n) is the total of line $n$ (or column $n$ ) in the distance matrix.

CONTORL VALUE: the control values are found by letting each node give the total value of 1 equally distributed to its connected nodes. The control value of node $\mathrm{n}, \mathrm{CV}$ (n) is the total value receive by node $\mathrm{n}$ during this operation.

Relative asymmetry: the relative asymmetry describes the integration of a node by a value between or equal to 0 and 1 , where a low value describes high integration. RA is calculated by formula $R A=2(M D-1) /(k-2) 4$. The RA-value is defined to be 0 when a node is as integrated as possible. The most integrated position possible is the root of a pure "bush"-graph. As all distances from such a root are 1 , the MD is 1 . By this RA=0 when $M D=1$. The RA might therefore be of the form $R A=a^{*}(M D-1)$. Contrary, RA is defined to be 1 when a node is as segregated as possible. The most segregated positions possible are the end nodes in a pure linear sequence. For a linear sequence of $\mathrm{k}$ nodes the MD for the end nodes is half the number of nodes in the line, $\mathrm{MD}=\mathrm{k} / 2$. By this: $\mathrm{RA}=1$ when $\mathrm{MD}=\mathrm{k} / 2$. This implies $1=\mathrm{a}^{*}(\mathrm{k} / 2-1)$ which gives $a=2 /(k-2)$. By this $R A=2 *(M D-1) /(k-2)$.

Mean Depth: mean depth for a node $\mathrm{n}$ is the average depth (or average shortest distance) from node $n$ to all other nodes. If $K$ is the total number of node in the system them MD (n) =TD (n)/ (k1) 
Integration value: a parameter that contrary to RA describes integration by a high number when node is highly integrated is the integration value (i). The integration value is found by inverting the RA, $i=1 / R A 5$. This is the integration value of RA. Integration might be defined as the inverse of other asymmetry parameters than the RA. (Manum, Rusten, \& Benze, GRAPH, Software for drawing and calculating space synatx Graphs).

Connecting spaces together have impact in what way integration is circulated throughout the structure. For instance, integration of spaces creates some areas in residential houses more accessible than others. The result of this organization consequences the interaction between residents and divides the spaces according to the activity that are located in it and not for the use of the public (Dawson, 2003). Hence, this research analyzed the traditional buildings with four different typological in Gilan provinces where has temperate-humid climate to understand the integration and segregation of the spaces.

\section{AGRAPH TOOL ANALYSIS}

Agraph tool is an application that can be used by computer easily. This method could be applicable for calculating space syntax. The plan of the building could be transferred to the drawing graph with Agraph application. Afterwards, Agraph calculated the parameter of space syntax from different kind of node(Manum, Rusten, \& Benze, n.d.).In this program all the close, semi-open and open spaces revealed by bullet. The line between the bullets demonstrated the connection of the spaces. The number that is visible in the bullet demonstrated the starting point of drawing graph step by step through all the spaces. For instance if the courtyard has number zero in the bullet, it means that graph started from the courtyard and then move to other spaces. Furthermore, this research did the analysis by concerning the three different starting point. One of the table (Table 5) illustrated the starting point from the close spaces. In table 7, graph drawn from the semi-open spaces such as Eyvan. Afterwards, table 9 open demonstrated the spaces like courtyard is the beginning step of drawing graph. The reason of changing the starting point (the carrier) is that the first bullet and connectivity of that one with the other space could change the calculation in the number of TDn, MDn, RA, integration value and CV. According to Hanson's definition of space syntax, the spaces which have more connection have less privacy than the other spaces. Hence the number in calculation, which is given to each space can be changed depending on how graph could be drawn. In this paper all the connectivity spaces like stair case also considered in the calculation for better understating of the integration between the spaces. Table 4 verified the meaning of 
Privacy Cognition of Spaces by Agraph Tools in Temperate Humid Climatic Region of Iran

the numbers that have been observed in the calculation of Agraph method. For instance, the highest number of TD, MDn and RA signify more privacy of spaces and also less integration. However, the highest number of I and CV represent the less privacy.

Table4: Definition of number in calculation with Agraph tool

\begin{tabular}{|c|c|c|c|}
\hline & & Private space & Public space \\
\hline \multicolumn{2}{|c|}{ Agraph tool } & \multicolumn{2}{|c|}{ number } \\
\hline TDn & Total depth & high & less \\
\hline MDn & Mean Depth & high & less \\
\hline RA & integration & high & less \\
\hline i & $\mathrm{i}=1 / \mathrm{RA}$ & less & high \\
\hline CV & Control value & less & high \\
\hline
\end{tabular}

By using Agraph tool in traditional buildings where are located in temperate-humid climate, the outcome demonstrated interesting variation depends on the starting point of the graph. For instance, in Table 5, closed spaces was the focal point of the Agraph analyses therefore, starting point was from one of the rooms.

Table 5: Calculating with Agraph tool from the closed space
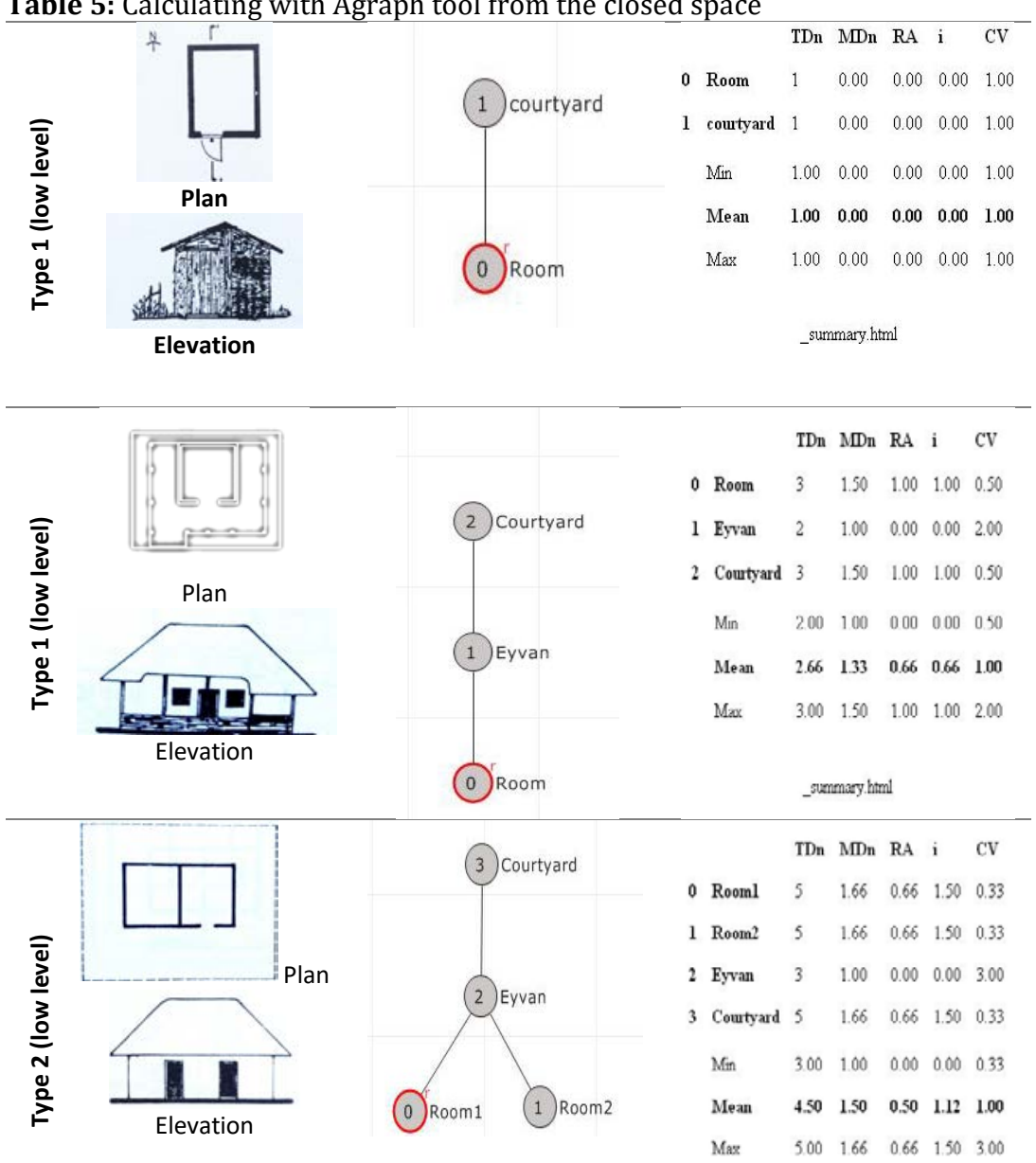

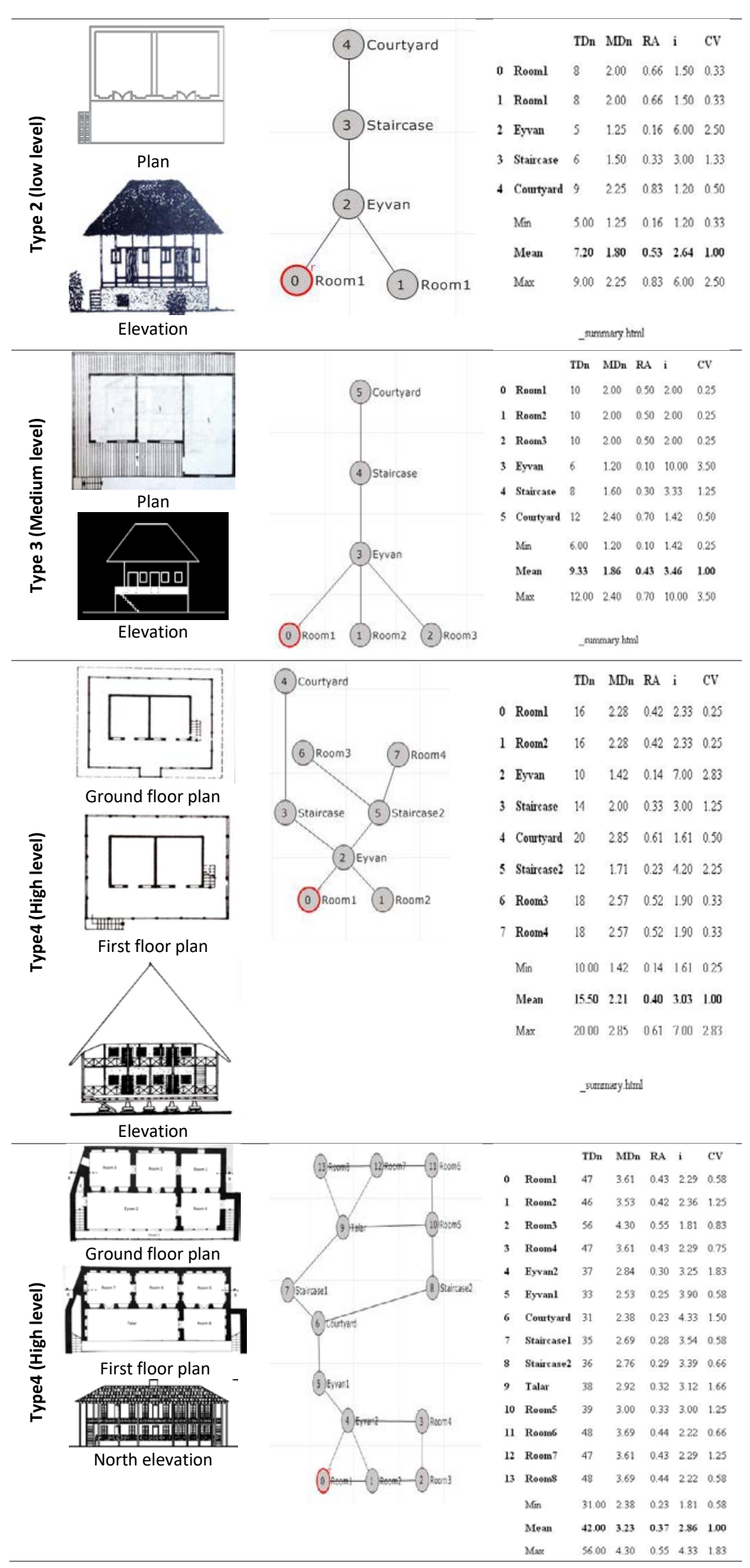
Privacy Cognition of Spaces by Agraph Tools in Temperate Humid Climatic Region of Iran

The result demonstrated that although the highest number of TDn, MDn and RA represent the more private space since they have less integration. However, the courtyard in all different kind of typology has the highest number. In the following the highest amount of integration and CV which represent the less privacy is belonging to room in the low economy houses. Also in the high economy condition, Eyvan has the highest integration value that represent more public spaces (Table 6).

Table 6: The result of Agraph tool from closed spaces

\begin{tabular}{lccccc}
\hline \multirow{2}{*}{$\begin{array}{l}\text { Economy } \\
\text { level }\end{array}$} & \multicolumn{5}{c}{ Close spaces } \\
\cline { 2 - 6 } & $\begin{array}{c}\text { TDn } \\
\text { (private) }\end{array}$ & $\begin{array}{c}\text { MDn } \\
\text { (private) }\end{array}$ & $\begin{array}{c}\text { RA } \\
\text { (private) }\end{array}$ & $\begin{array}{c}\text { I } \\
\text { (public) }\end{array}$ & $\begin{array}{c}\text { CV } \\
\text { (public) }\end{array}$ \\
\cline { 2 - 6 } $\begin{array}{l}\text { Type 1 } \\
\text { low level }\end{array}$ & $\begin{array}{c}\text { Room/ } \\
\text { courtyard }\end{array}$ & - & - & - & - \\
\hline $\begin{array}{l}\text { Type 1 } \\
\text { low level }\end{array}$ & $\begin{array}{c}\text { Room/ } \\
\text { courtyard }\end{array}$ & $\begin{array}{c}\text { Room/ } \\
\text { courtyard }\end{array}$ & $\begin{array}{c}\text { Room/ } \\
\text { courtyard }\end{array}$ & $\begin{array}{c}\text { Room/ } \\
\text { courtyard }\end{array}$ & Eyvan \\
\hline $\begin{array}{l}\text { Type 2 } \\
\text { low level }\end{array}$ & $\begin{array}{c}\text { Room/ } \\
\text { courtyard }\end{array}$ & $\begin{array}{c}\text { Room/ } \\
\text { courtyard }\end{array}$ & $\begin{array}{c}\text { Room/ } \\
\text { courtyard }\end{array}$ & $\begin{array}{c}\text { Room/ } \\
\text { courtyard }\end{array}$ & Eyvan \\
\hline $\begin{array}{l}\text { Type 2 } \\
\text { low level }\end{array}$ & courtyard & courtyard & courtyard & Eyvan & Eyvan \\
\hline $\begin{array}{l}\text { Type 3 } \\
\text { medium } \\
\text { level }\end{array}$ & courtyard & courtyard & courtyard & Eyvan & Eyvan \\
\hline $\begin{array}{l}\text { Type 4 } \\
\text { high level }\end{array}$ & courtyard & courtyard & courtyard & Eyvan & Eyvan \\
\hline $\begin{array}{l}\text { Type 4 } \\
\text { high level }\end{array}$ & Room3 & Room3 & Room3 & courtyard & $\begin{array}{c}\text { Room3/ } \\
\text { Eyvan2 }\end{array}$ \\
\hline
\end{tabular}

Table 7 exemplified the Agraph tool by changing the starting point from semi-open spaces such as Eyvan. In low economy condition of the building where has only one bedroom, the integration value of all the spaces is same. Furthermore, the degree of public and privacy of the room, entrance and Eyvan are represent the same result. In medium economic condition the number of TDn, MDn and RA signify that room has more privacy than the other spaces. Furthermore, entrance has highest degree of integration value. Consequently, Eyvan (semi-open space) is more public.

Table 7: Calculating with Agraph tool from semi-open space

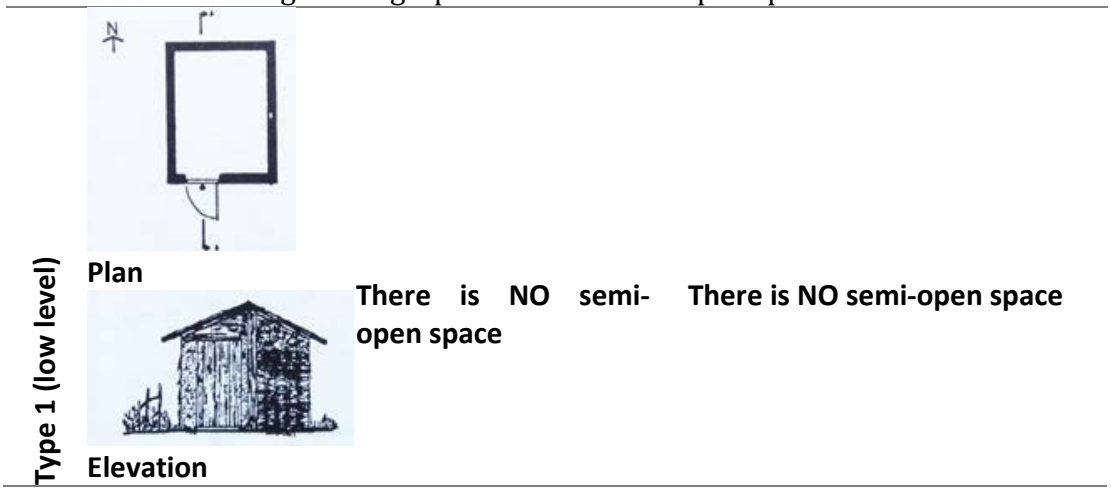




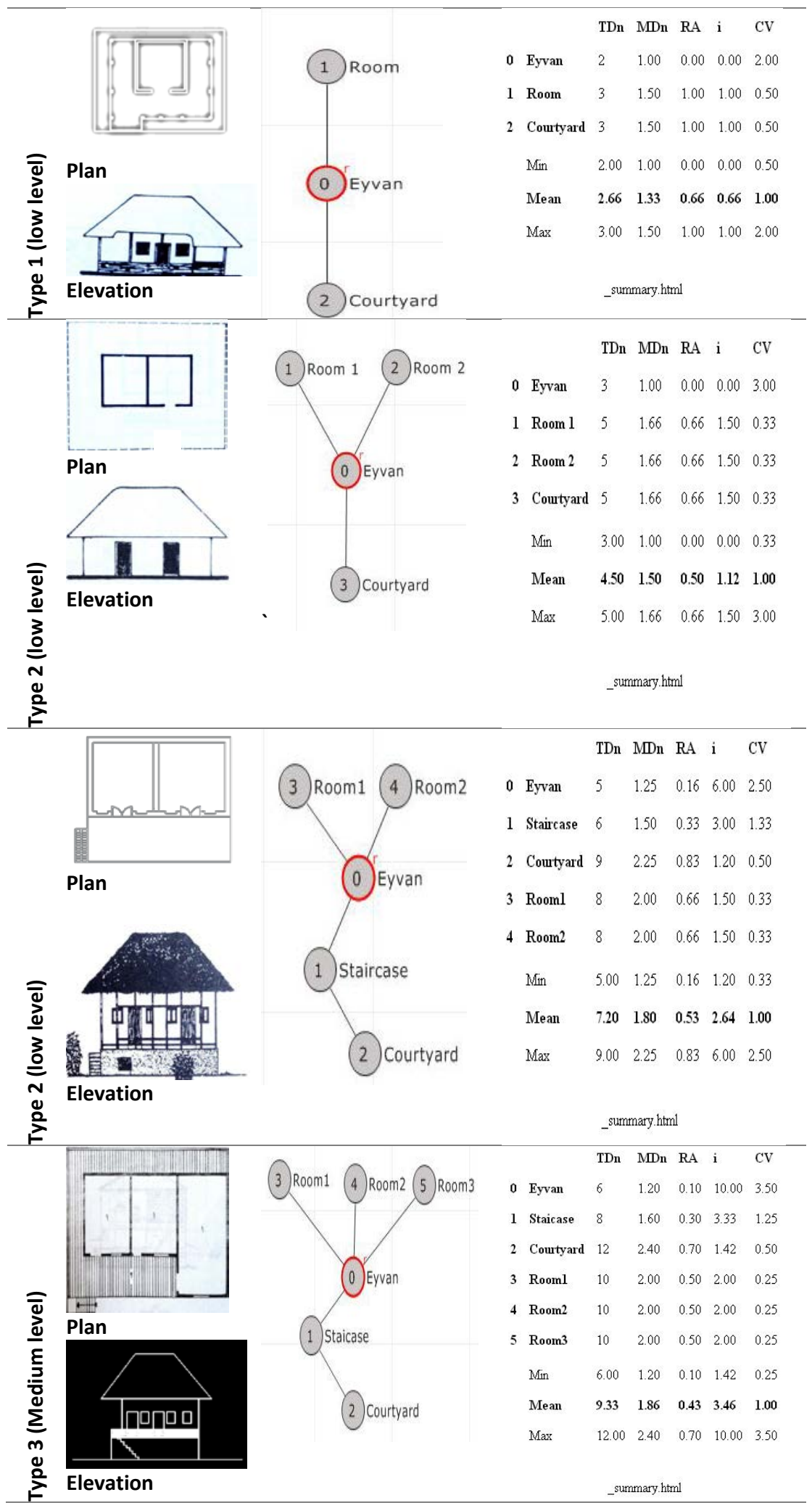




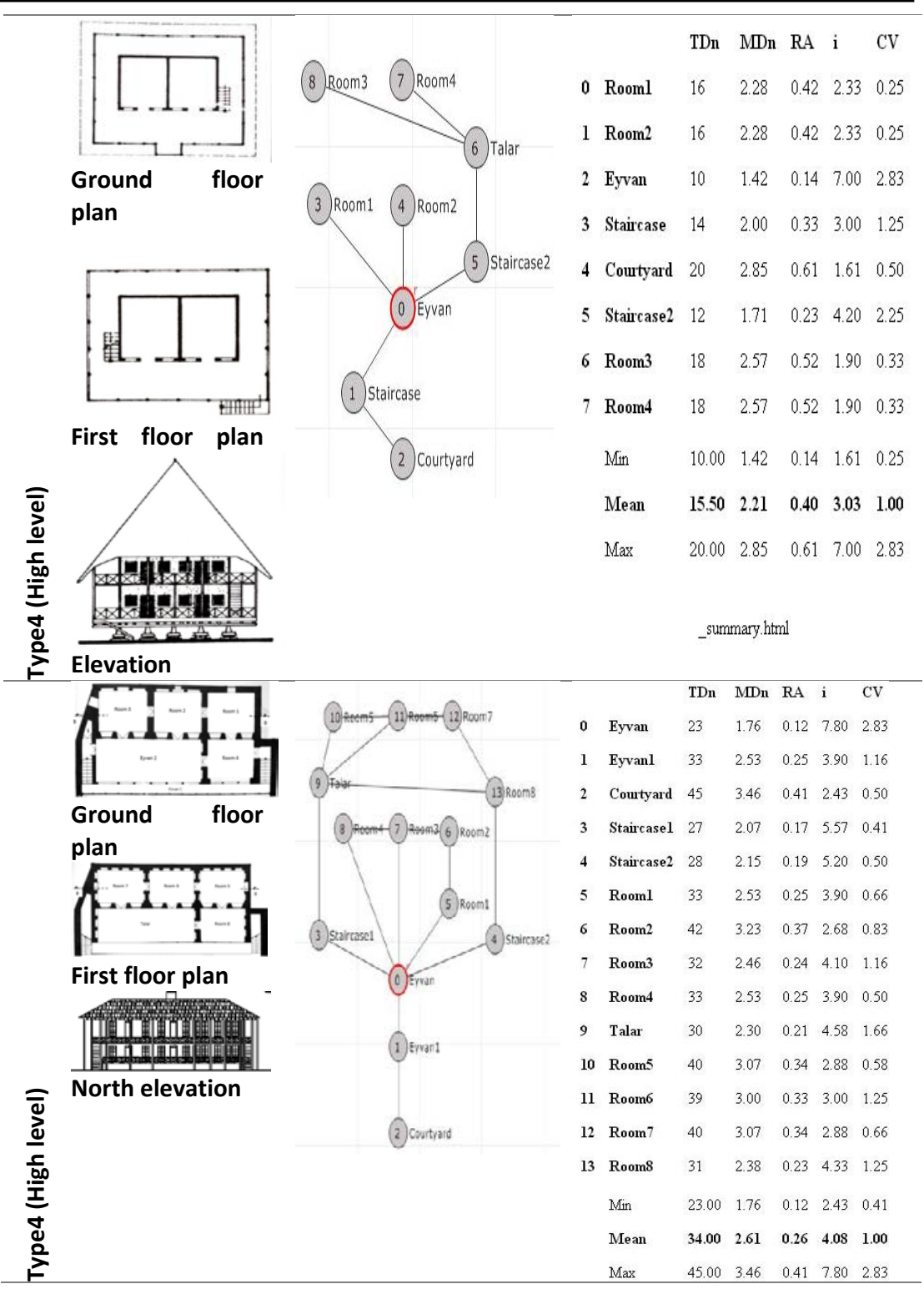

In Table 8 the result of high level of economy which has more than three bedrooms are totally different. Calculation verified that entrance has more privacy by having higher value of TDn , MDn and RA although entrance cannot be private space by comparing to the rooms. Moreover, the integration value and CV of these houses represent that Eyvan has the highest public value which, the result is meaningful and accurate.

The last analysis is the one that started the calculation from the entrance (open space). Investigating the building for evaluating the degree of privacy and public could be more reasonable if the starting point began from the entrance area. In Table 9 same as the previous analysis the result of TDn and CV are same in low economy condition. It means that the degree of public and privacy is same in both room and entrance. This outcome is wrong and it cannot be acceptable. In addition, room in the medium level of economy has more privacy, and entrance has 
less privacy by comparing to each other. Conversely, room in this analysis signifies the highest integration since it has more degree of integration value and CV that is not acceptable by comparing to the entrance and courtyard area.

Table 8: The result of Agraph tool from semi-open spaces

\begin{tabular}{|c|c|c|c|c|c|}
\hline \multirow{3}{*}{$\begin{array}{l}\text { Economy } \\
\text { level }\end{array}$} & \multicolumn{5}{|c|}{ Semi-open space } \\
\hline & \multicolumn{5}{|c|}{ The highest number } \\
\hline & $\begin{array}{l}\text { TDn } \\
\text { (private) }\end{array}$ & $\begin{array}{l}\text { MDn } \\
\text { (private) }\end{array}$ & $\begin{array}{l}\text { RA } \\
\text { (private) }\end{array}$ & $\begin{array}{l}\text { I } \\
\text { (public) }\end{array}$ & $\begin{array}{l}\text { CV } \\
\text { (public) }\end{array}$ \\
\hline $\begin{array}{l}\text { Type } 1 \\
\text { low level }\end{array}$ & - & - & - & - & - \\
\hline $\begin{array}{l}\text { Type } 1 \\
\text { low level }\end{array}$ & $\begin{array}{l}\text { Room/ } \\
\text { courtyard }\end{array}$ & $\begin{array}{l}\text { Room/ } \\
\text { courtyard }\end{array}$ & $\begin{array}{l}\text { Room/ } \\
\text { courtyard }\end{array}$ & $\begin{array}{l}\text { Room/ } \\
\text { courtyard }\end{array}$ & Eyvan \\
\hline $\begin{array}{l}\text { Type } 2 \\
\text { low level }\end{array}$ & $\begin{array}{l}\text { Room/ } \\
\text { courtyard }\end{array}$ & $\begin{array}{l}\text { Room/ } \\
\text { courtyard }\end{array}$ & $\begin{array}{l}\text { Room/ } \\
\text { courtyard }\end{array}$ & $\begin{array}{l}\text { Room/ } \\
\text { courtyard }\end{array}$ & Eyvan \\
\hline $\begin{array}{l}\text { Type } 2 \\
\text { low level }\end{array}$ & courtyard & courtyard & courtyard & Eyvan & Eyvan \\
\hline $\begin{array}{l}\text { Type } 3 \\
\text { medium } \\
\text { level }\end{array}$ & courtyard & courtyard & courtyard & Eyvan & Eyvan \\
\hline $\begin{array}{ll}\text { Type } & 4 \\
\text { high } & \\
\text { level } & \\
\end{array}$ & courtyard & courtyard & courtyard & Eyvan & Eyvan \\
\hline $\begin{array}{l}\text { Type } \\
\text { high } \\
\text { level }\end{array}$ & courtyard & courtyard & courtyard & Eyvan & Eyvan \\
\hline
\end{tabular}

Table 9: Calculating with Agraph tool from open space

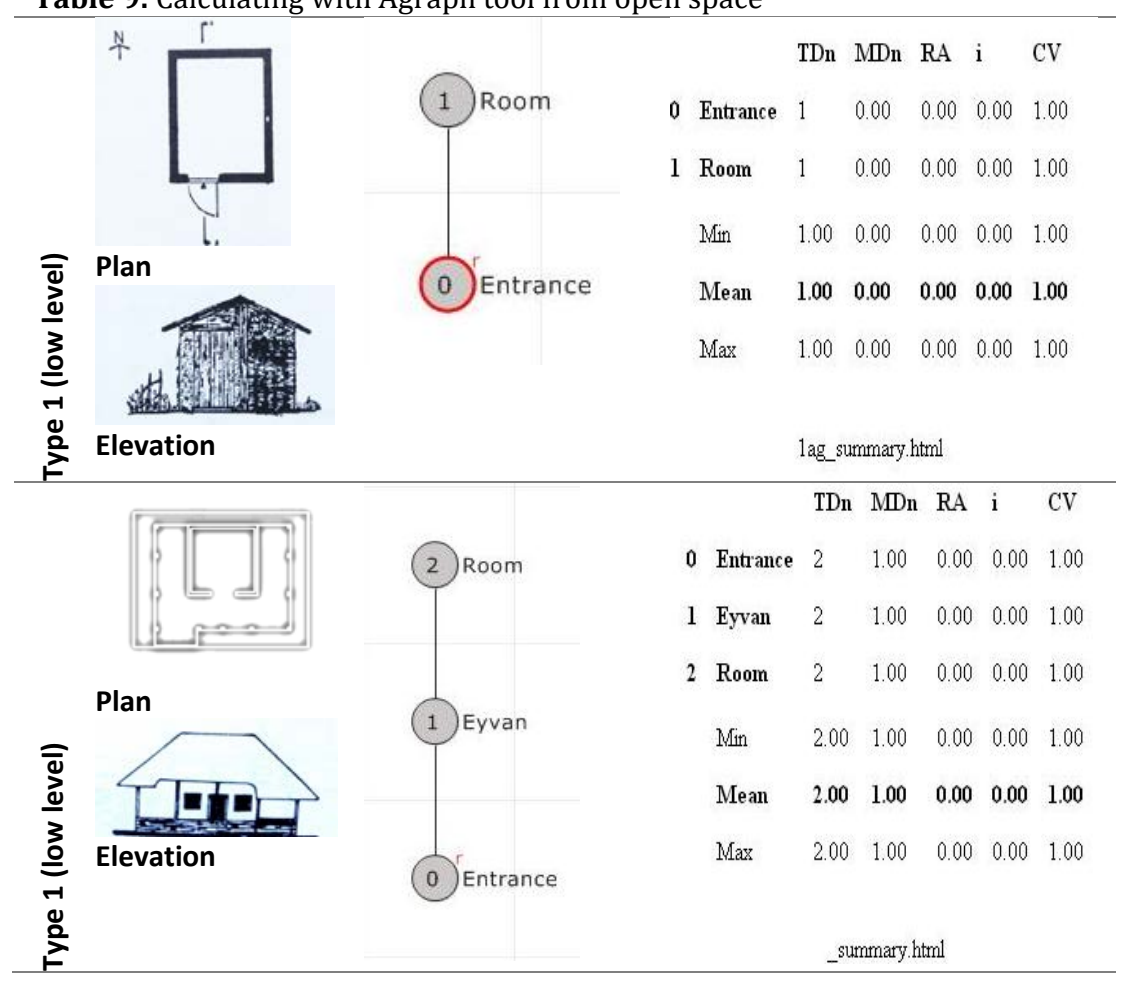


Privacy Cognition of Spaces by Agraph Tools in Temperate Humid Climatic Region of Iran

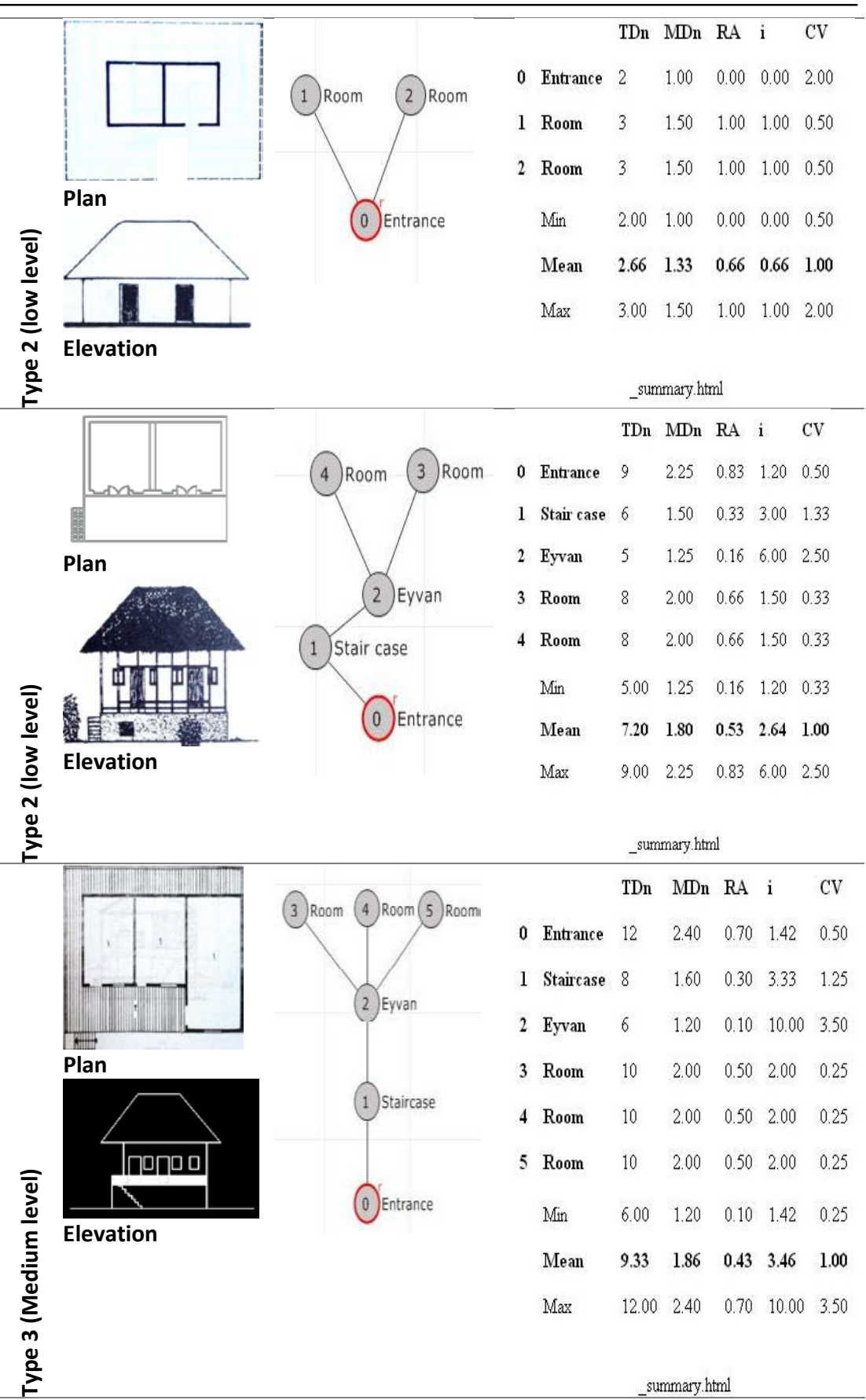




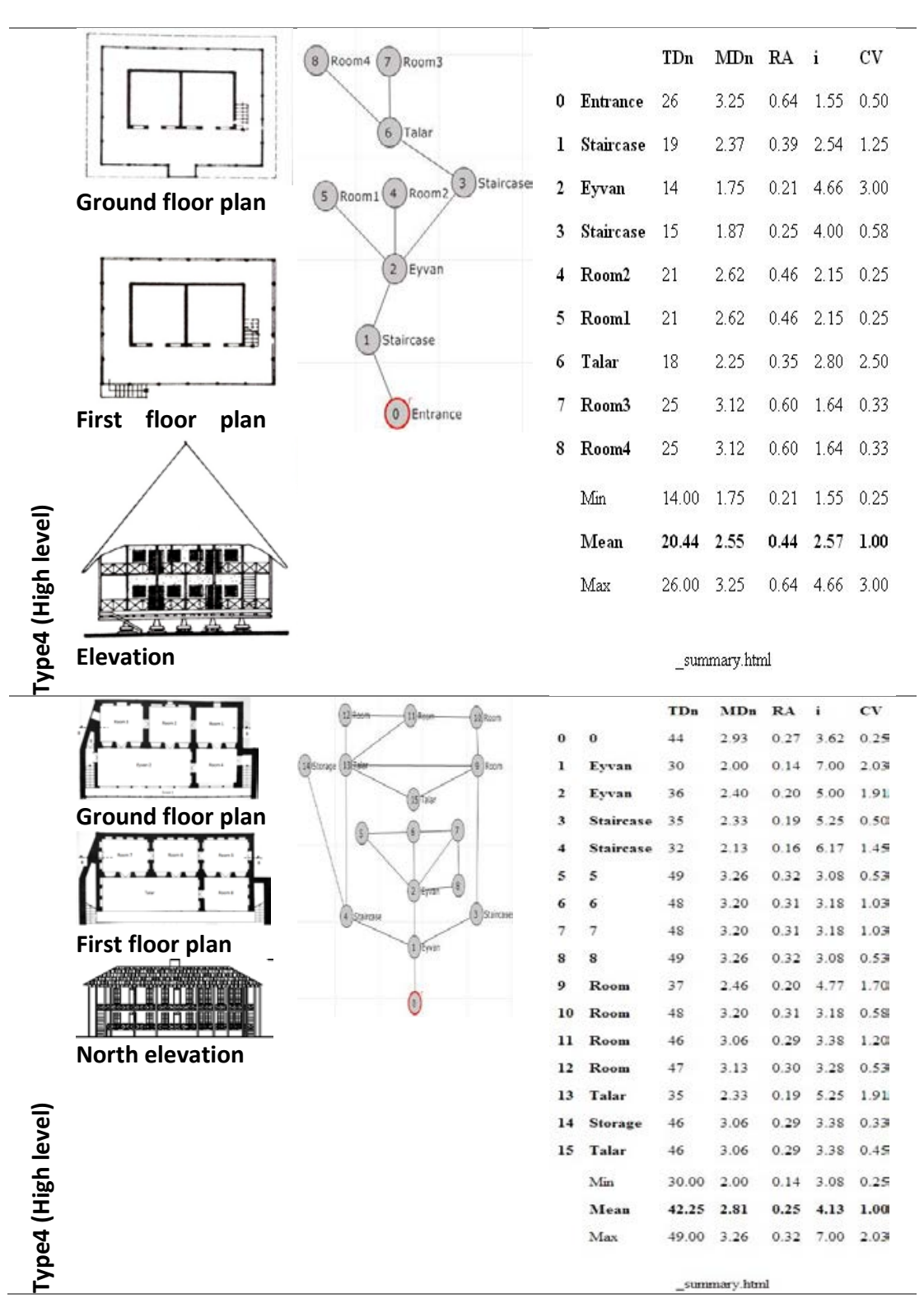

Furthermore, the result in high economy level is varied because of differentiation in number of bedrooms. For instance, in traditional building which has three rooms the result is same. But in the four bedrooms the result is different. In three bedrooms building, entrance area has revealed as the private space and Eyvan as the public space concerning with the number of TDn, MDn, RA, integration value and CV. This result is not conventional since entrance is the first space that everyone should pass through it for entering to the house. So the entrance (open space) cannot be considered as a private space and it is more public. But the result of Eyvan (semi-open space) which is more public spaces in these kind of buildings is logical. For the reason that the resident in this humid climate spend most of the evening time in Eyvan. For the reason that Eyvan is cool and it has comfortable condition during the spring and the summer time for the inhabitants in this climate (Table10). 
Privacy Cognition of Spaces by Agraph Tools in Temperate Humid Climatic Region of Iran

Table 10: The result of Agraph tool from open spaces

\begin{tabular}{|c|c|c|c|c|c|}
\hline \multirow{3}{*}{$\begin{array}{l}\text { Economy } \\
\text { level }\end{array}$} & \multicolumn{5}{|c|}{ Space syntax for simulating the privacy in traditional building } \\
\hline & \multicolumn{5}{|c|}{ The highest number } \\
\hline & $\begin{array}{l}\text { TDn } \\
\text { (private) }\end{array}$ & $\begin{array}{l}\text { MDn } \\
\text { (private) }\end{array}$ & $\begin{array}{l}\text { RA } \\
\text { (private) }\end{array}$ & I & CV (public) \\
\hline $\begin{array}{l}\text { Type } 1 \text { low } \\
\text { level }\end{array}$ & $\begin{array}{l}\text { Room/ } \\
\text { entrance }\end{array}$ & - & - & - & Room/entrance \\
\hline $\begin{array}{l}\text { Type } 1 \text { low } \\
\text { level }\end{array}$ & $\begin{array}{l}\text { Room/ } \\
\text { Eyvan / } \\
\text { entrance }\end{array}$ & - & - & - & $\begin{array}{l}\text { Room/ Eyvan / } \\
\text { entrance }\end{array}$ \\
\hline $\begin{array}{l}\text { Type } 2 \text { low } \\
\text { level }\end{array}$ & Room & Room & Room & Room & entrance \\
\hline $\begin{array}{l}\text { Type } 2 \text { low } \\
\text { level }\end{array}$ & entrance & entrance & entrance & Eyvan & Eyvan \\
\hline $\begin{array}{l}\text { Type } \\
\text { medium } \\
\text { level }\end{array}$ & entrance & entrance & entrance & Eyvan & Eyvan \\
\hline $\begin{array}{l}\text { Type } 4 \text { high } \\
\text { level }\end{array}$ & entrance & entrance & entrance & Eyvan & Eyvan \\
\hline $\begin{array}{l}\text { Type } 4 \text { high } \\
\text { level }\end{array}$ & $\begin{array}{l}\text { Room5/ } \\
\text { room8 }\end{array}$ & $\begin{array}{l}\text { Room5/ } \\
\text { room8 }\end{array}$ & $\begin{array}{l}\text { Room5/ } \\
\text { room8 }\end{array}$ & Eyvan1 & Eyvan1 \\
\hline
\end{tabular}

\section{Disscussion}

The graphs and calculation analysis that the starting point is from the entrance (open space), represent the outcome in a way that if the building has only one or two bedrooms, all the spaces such as room, Eyvan and even entrance have same degree of integration. Thus there is same privacy in all of the spaces. In addition, spaces in traditional building with two bedrooms where are classified in low level of economy have different kind of segregation. For instance, rooms have degree of more privacy and Eyvan is more public. Although in some of the case in the same level of economy, entrance displays more privacy which the outcome is conflict. Furthermore, in medium and high level of economy, accruing to the result of AGRAPH, entrance has specific role that demonstrated less integration and so more privacy. Consequently, calculation of TDn, MDn,RA is not response with the routine life of the inhabitant in this temperatehumid climate. For the reason that entrance could never be the space with more privacy comparing with rooms. In other calculation with semi-open and close space as a starting point, the outcome is the same. Meanwhile, in all the level of economy, the courtyard has more privacy than other spaces. Although in some analysis room got the same number like courtyard where signify more privacy but these spaces are not comparable with each other.

$\mathrm{CV}$ in all the analysis and calculation of traditional building in different level of economy illustrate the same result. Eyvan in Agraph analysis has more integration therefore, has less privacy. Successively, Eyvan is comfortable space for the inhabitants in this humid climate, since wind could flow through it, so the outcome is accurate. 


\section{CONCLUSION}

Space syntax analysis is one of the best methods for the architect to comprehend the integration and segregation of the spaces. Also by considering the segregation and integration, the degree of privacy and public of the space could be reasonable. Agraph tool by drawing graph and doing calculation could easily represent all these issue. This research did the analysis with Agraph tool on traditional buildings where are located in temperate-humid climate of Iran. In this climate semi-open and open space since of humidity condition has an important role for the gathering of the inhabitant and also connecting the spaces such as rooms all together. Though, the result of Agraph analysis has conflict with the method of life that the inhabitant have in this climate. One of the problems is related to the drawing of the justified graph. For instance, starting drawing the graph from rooms could give different calculation than starting from entrance or any other spaces. In architecture the basic method for reading the building is from the entrance point. Therefore, the proper result could be the justified graph that is started from entrance point (open space). However, this paper did the analysis from semi-open and closed space as well to have comprehensive result. The outcome of the analysis confirmed that although Agraph tool is the easiest way for understanding the degree of segregation and integration of the spaces but it cannot be accurate from the option of TDn, MDn and RA evaluation. As regards, the $\mathrm{Cv}$ and I evaluation in the analysis of traditional building represent the accurate result. The future studies of this research could be finding the solution for covering this gap in Agraph tool for better figuring out the social relation of the spaces based on space syntax method.

\section{REFERENCE}

Blanton, R. E. (1994). Houses and Households. New York: A Comparative Study.

Darab, D., \& Yaghini, S. (1998). Local architecture of Gilan. Memari va shahrsazi.

Dawson, C. P. (2003). Examining the impact of EuroCanadian architecture on Inuit families living in Arctic Canada. . J. Hanson (Ed.) Proceedings: Space Syntax: 4th International Symposium, 1 (2), p.4.

Hanson, J. (1998). Decoding Houses and Homes. Cambridge: Cambridge press.

Hiller, B. (1984). The Social Logic of Space. Cambridge: Cambridge University Press.

Hillier, B. (1996). Space is the Machine. Cambridge: Cambridge University Press.

Lawrence, D. L. (1990). The Built Environment and Spatial Form. Vol.19, pp.453-505. 
Manum, B. (2009). AGRAPH;Complementary Software for AxialLine Analysis. In Proceedings of the 7th International Space Syntax Symposium, (pp. 1-9). Sweeden, Stockholm.

Manum, B., Rusten , E., \& Benze, P. (n.d.). AGRAPH, Software for Drawing and Calculating Space Syntax Graphs. Norway: Oslo School of Architecture.

Markus, T. A. (1993). Buildings and Power: Freedom and Control in the Origin of Modern Building Types. Routledge: London.

Martin, S. (2001). Court and Realm: Architectural Signatures in theSouthern Maya Lowlands. Colorado: Westview Press.

Pourvahidi, P., \& Ozdeniz, M. (2013). Bioclimatic analysis for iranian climate for energy conservation in architecture. scientific research and essay,Vol.8(1) pp. 7-16.

Rapoport, A. (1968). House Form and Function. New Jersey: Foundation of CulturalGeography Series. Prentice Hal.

Rezaeirad, R. (1998). Architecture of guilan, human and nature. Iran: memari va shahrdazi (24).

Sajjadzadeh, H. M. (2016, September). Relationship between the form of building and traditional architecture elements with the comfort of the homes of Gilan. National Conference on Civil engineering and Architecture with focus on sustainable development. Iran.

Trigger, B. G. (1989). Monumental Architecture: A ThermodynamicExplanation of Symbolic Behaviour. Cambridge: CambridgeUniversity Pres.

Urry, J. (1987). Society, Space and locality. Environmnet and planning, vol.5, issue.4, pp.435-444.

Vursho, B., \& Yunnistyna, A. (2016). Space syntax analysis in the albanian dwellings. Scientific Research and Information Technology, Vol. 6(1) 95-106.

Yaran, A. M. (2013). Adaptation of Indigenous Indicators of Gilan with Modern Western Architecture. Journal of Architecture and Urban Planning, 15, p.169-179.

\section{Resume}

Parastoo Pourvahidi is an Assistant Professor in the Department of Architecture at Cyprus International University, where she has been since 2018. From 2017 to 2018 she served as Department Chair of architecture department in Islamic Azad University (Tehran North branch). . Her research interests span both climatic design and space syntax theory. 